\title{
Incidence of sarcoidosis in the Isle of Man
}

\author{
STEPHANIE A PARKES, SB DE C BAKER, RE BOURDILLON, CRH MURRAY, \\ M RAKSHIT, JWR SARKIES, JP TRAVERS, EW WILLIAMS
}

From Nobles Hospital, Isle of Man

\begin{abstract}
The incidence of sarcoidosis in a clearly defined island community has been determined in a seven year study. Special efforts were made to identify all cases, including those presenting to their general practitioners with only minor symptoms. A mean incidence of 14.7 per 100000 per annum has been found in the years 1977-83 compared with an annual incidence of 3.5 per 100000 in the preceding 15 years, when no specific attempts were made to identify sufferers from sarcoidosis. The lower figure is similar to the reported incidence in the United Kingdom and the difference is considered to be due to increased detection of cases during the study period. These findings suggest that a large proportion of cases of sarcoidosis in a general population may not be recorded in a registration system.
\end{abstract}

The true incidence of sarcoidosis in any community has proved to be very difficult to assess for several reasons. Firstly, an unknown proportion of cases are undetected because the disease is subclinical or symptoms are mild; secondly, patients can present to almost any specialty and cases are not always recorded in a central register; thirdly, the size of the population served by the unit or hospital cannot always be estimated; and, finally, although the definition of the disease can be precise ${ }^{1}$ the practical application of this to mild cases presents difficulties.

The Isle of Man has considerable advantages for epidemiological studies in that it has a clearly defined boundary and a relatively stable resident population of about 60000 people, which is enumerated by a regular census ${ }^{2}$ giving information on occupations, ages, country of birth, and distribution of residences. There is one centrally organised health service with one main general hospital and a unified medical record system. There is good cooperation between the relatively few consultants in the various specialties and with the 32 general practitioners serving the island population.

The object of the study was to determine the incidence of sarcoidosis prospectively over several years. We recognised that to find most cases presenting within a defined period we would not only have to obtain the cooperation of all the specialists who might see patients but also have to enlist the help of

Address for reprint requests: Dr SB de C Baker, Nobles Hospital, Douglas, Isle of Man.

Accepted 20 November 1984 the general practitioners and encourage them to refer patients with symptoms possibly due to sarcoidosis to an appropriate consultant.

A comparison is made between the numbers and types of case occurring in the years 1977-83, when every effort was made to find all cases, and those found during the 15 years before this.

\section{Patients and methods}

In 1977 the general practitioners were visited and sent a written reminder of the signs and symptoms of the disease and asked to refer all possible cases to one of the clinical consultants for further investigation. The response was excellent and interest in the project was maintained for the seven years. Radiologists also called attention to possible cases among both inpatient and outpatients having chest radiographs. The hospital records were examined for cases occurring during the 15 years before 1977 . The diagnosis was based on the definition of the disease agreed at the Seventh International Conference on Sarcoidosis and other Granulomatous Diseases.' A biopsy or a Kveim test was done in all cases of possible sarcoidosis occurring after 1977. On completion of the seven year period of the study the clinical notes and radiographs of all the cases investigated since 1962 were submitted to a physician with wide experience of sarcoidosis (Dr DN Mitchell, Medical Research Council Tuberculosis and Chest Disease Unit, Brompton Hospital) for an independent assessment of each case. All histological sections were reexamined under blind condi- 
tions. Only those cases considered as definite clinical sarcoidosis were included. The cases were classified according to their main presenting symptoms and signs and by age and sex; the distribution of cases in all categories during 1962-76 was compared with that for 1977-83 and the differences assessed by the $\chi^{2}$ test. Incidence was calculated from the resident population figures given in the 1961, 1966, 1971, 1976 , and 1981 Isle of Man Census reports. ${ }^{2}$ It is expressed as the number of cases per 100000 people per year, and has been abbreviated throughout the text to the incidence figure alone.

\section{Results}

During 1962-83 there were 96 cases of sarcoidosis. After independent assessment 94 of these were judged to be clinically definite; one was excluded because of concomitant tuberculosis and another, in a child of 11 years, because of insufficient evidence. Of the 94 cases, $70(75 \%)$ were Kveim positive or had other histological confirmation of the diagnosis. The annual incidence in the years $1962-76$ was 3.5 , compared with 14.7 during 1977-83 (table 1). Analysis of the incidence of the disease by age at diagnosis and by sex shows that there is no significant sex difference at any age, either before $(p>0.50)$ or after $1977(0.50>p>0.10)$. The ratio of male to female cases $(1: 1.2)$ corresponds with the male to female ratio in the whole population (1:1.1). Most patients of both sexes were 25-40 years of age, although more older patients were diagnosed in the second period, five being over 70 years old (table 2 ).

A comparison of the numbers of cases presenting in different ways in the two periods under consideration is given in table 3 . There is no significant differ-

Table 1 Incidence of sarcoidosis in the Isle of Man from 1962 to 1983

\begin{tabular}{lclc}
\hline Years & No of cases & $\begin{array}{l}\text { Size of resident } \\
\text { population }\end{array}$ & $\begin{array}{l}\text { Crude incidencel } \\
\text { 100 000/y }\end{array}$ \\
\hline $1962-6$ & 8 & 49278 & 3.3 \\
$1967-71$ & 10 & 52502 & 3.8 \\
$1972-6$ & 10 & 57539 & 3.5 \\
Total & 28 & & Mean 3.5 \\
1977 & 8 & 61332 & 13.0 \\
1978 & 6 & 62169 & 9.6 \\
1979 & 8 & 63005 & 12.7 \\
1980 & 10 & 63842 & 15.7 \\
1981 & 11 & $64679 \dagger$ & 17.0 \\
1982 & 11 & 65515 & 16.9 \\
1983 & 12 & 66351 & 18.0 \\
Total & 66 & & Mean 14.7 \\
\hline
\end{tabular}

*For 1962-6, 1967-71, and 1972-6 mean population sizes are given; for 1977-80, 1982, and 1983 the figures are all extrapolated from the resident population census figures for 1976 and 1981 . †Actual resident population.
Table 2 Incidence of sarcoidosis in the Isle of Man during $1962-76$ and $1977-83$ by age and sex

\begin{tabular}{|c|c|c|c|}
\hline \multirow{2}{*}{$\begin{array}{l}\text { Age (y) at } \\
\text { diagnosis }\end{array}$} & \multicolumn{3}{|c|}{ No of cases 1962-76 (incidence/100 000/y) } \\
\hline & Male & Female & Total \\
\hline $\begin{array}{c}0-14 \\
15-19 \\
20-24 \\
25-29 \\
30-34 \\
35-39 \\
40-49 \\
50-59+\end{array}$ & $\begin{array}{l}0(0) \\
1(3.9) \\
2(9.1) \\
2(9.6) \\
2(10.2) \\
4(20.1) \\
1(2.4) \\
1(0.7)\end{array}$ & $\begin{array}{l}0(0) \\
1(4.0) \\
4(17.7) \\
4(19.0) \\
1(5.1) \\
1(4.7) \\
2(4.1) \\
2(1.1)\end{array}$ & $\begin{array}{l}0(0) \\
2(3.9) \\
6(13.4) \\
6(14.3) \\
3(7.6) \\
5(12.1) \\
3(3.3) \\
3(0.9)\end{array}$ \\
\hline Total & $13(3.5)$ & $15(3.5)$ & $28(3.5)$ \\
\hline \multirow{2}{*}{$\begin{array}{l}\text { Age (y) at } \\
\text { diagnosis }\end{array}$} & \multicolumn{3}{|c|}{ No of cases 1977-83 (incidence/100 000/y) } \\
\hline & Male & Female & Total \\
\hline $\begin{array}{c}0-14 \\
15-19 \\
20-24 \\
25-29 \\
30-34 \\
35-39 \\
40-49 \\
50-59+\end{array}$ & $\begin{aligned} 0 & (0) \\
2 & (12.7) \\
1 & (7.3) \\
1 & (7.1) \\
3 & (21.3) \\
7 & (56.1) \\
4 & 17.6) \\
12 & (16.1)\end{aligned}$ & $\begin{aligned} 0 & (0) \\
0 & (0) \\
4 & (29.0) \\
6 & (43.4) \\
10 & (71.9) \\
4 & (32.5) \\
4 & (17.2) \\
8 & (8.1)\end{aligned}$ & $\begin{aligned} & 0(0) \\
& 2(6.4) \\
& 5(18.2) \\
& 725.0) \\
& 13(46.4) \\
& 11(44.4) \\
& 8(17.4) \\
& 20(11.6)\end{aligned}$ \\
\hline Total & $30(14.1)$ & $36(15.4)$ & $66(14.7)$ \\
\hline
\end{tabular}

Table 3 Predominant modes of presentation of 94 cases of sarcoidosis

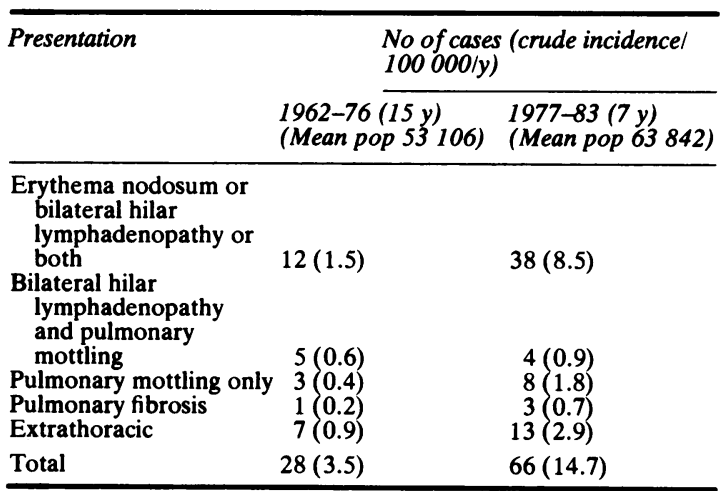

ence between the distribution of presenting features in the two groups $(0.50>p>0.10)$.

\section{Discussion}

The reported incidence of sarcoidosis from various sources worldwide is very variable and reflects the different methods that have been used to detect cases. Table 4 summarises the published figures with comments on the methods used and compares these with the incidence figures obtained in this study.

The incidence in the Isle of Man 1962-76 is similar to that found in a survey in four areas in the UK 
Table 4 Published crude incidence rates of sarcoidosis (per 100000 per year)

\begin{tabular}{|c|c|c|c|}
\hline Country & $\begin{array}{l}\text { Period and } \\
\text { reference }\end{array}$ & Incidence & Comments \\
\hline Denmark & $\begin{array}{l}1962-71^{3} \\
1962-71^{4} \\
1960-69^{4}\end{array}$ & $\begin{array}{r}5.0 \\
14.0 \\
10.8\end{array}$ & $\begin{array}{l}\text { Cases registered at chest clinics and medical departments } \\
\text { Annual incidence in cases screened for tuberculosis } \\
\text { Study in one region of Denmark }\end{array}$ \\
\hline Finland & $1968-70^{5}$ & 7.5 & Hospital cases and mass radiography \\
\hline Czechoslovakia & $1974^{6}$ & 2.3 & Hospitals and chest clinics \\
\hline Italy & $1967-71^{7}$ & 3.0 & Mass radiography \\
\hline United Kingdom & $1961-66^{8}$ & 3.25 & $\begin{array}{l}\text { Survey from four areas with physicians, dermatologists, ophthalmologists, and chest clinics } \\
\text { taking part }\end{array}$ \\
\hline & $1950-63^{9}$ & 8.3 & Radiographic follow up after BCG vaccination of $15-25$ year olds \\
\hline Japan & $\begin{array}{l}1975-10 \\
1966-70^{11}\end{array}$ & 0.5 & $\begin{array}{l}\text { Nationwide questionnaire } \\
\text { Clinical cases and mass radiography }\end{array}$ \\
\hline $\begin{array}{l}\text { Sweden } \\
\text { Isle of Man }\end{array}$ & $\begin{array}{l}1963-78^{12} \\
1962-76 \\
1977-83\end{array}$ & $\begin{array}{l}19.0^{*} \\
3.5 \\
14.7+\end{array}$ & $\begin{array}{l}\text { Regular radiographic screening } \\
\text { Retrospective study of cases referred to hospital } \\
\text { Prospective study with special effort to detect cases }\end{array}$ \\
\hline
\end{tabular}

*In a population aged 15 years and over.

$\dagger 17.0$ in a population aged 15 years and over.

in 1961-66. ${ }^{8}$ It was carried out by asking consultant physicians, dermatologists, and ophthalmologists to submit details of possible cases to a central panel. The mean incidence was 3.25 , compared with our figure of 3.5 obtained by the retrospective study of the hospital records. In both investigations it is believed that most cases referred to a hospital consultant have been recorded. From 1977 to 1983 in the Isle of Man special efforts were made to find cases, many of which under other circumstances would never have been referred to hospital. This effort increased the number found fourfold, to an incidence of 14.7 per 100000 . This figure is similar to the annual incidence found in patients who are screened for tuberculosis in Denmark ${ }^{4}$ and in people undergoing a general health survey in Sweden. ${ }^{12}$

There is no evidence to suggest that there has been a real change in the incidence of sarcoidosis in the Isle of Man, affecting all age groups, coinciding with the start of the detailed survey that could account for a sustained fourfold increase. Much more probably, the change is due to increased detection of cases. Tables 2 and 3 show that there was no change in relative frequency of the various modes of presentation, age at diagnosis, or sex ratio between the two periods. This study has shown that modest clinical efforts to improve the recognition of sarcoidosis have greatly increased the apparent incidence. Even this incidence of 14.7 , however, is likely to be an underestimate, since not all patients with minor symptoms will consult their general practitioner, while there are other persple with completely subclinical disease.

Our experience of an improved detection rate in the Isle of Man probably applies equally to all other regions, and if it does differences in detection rate are likely to invalidate comparisons of incidence rates from various parts of the world and to mask differences due to other factors such as climate, latitude, and race. The detection of only a small proportion of the total cases will also hamper progress in the study of the disease by epidemiological methods.

We are indebted to Dr DN Mitchell of the Medical Research Council (MRC) Tuberculosis and Chest Diseases Unit at the Brompton Hospital, London, and to Dr I Sutherland of the MRC Biostatistics Unit, Cambridge, for their help and encouragement. We are grateful to the general practitioners of the Isle of Man, whose vigilance and cooperation enabled us to find and investigate the cases of sarcoidosis. The research was supported by the Council of the Isle of Man Postgraduate Medical Centre.

\section{References}

1 James DG, Turiaf J, Hosoda Y, et al. Description of sarcoidosis: report of the sub-committee of classification and definition. In: Siltzbach LE, ed. Proceedings of the Seventh International Conference on Sarcoidosis and other Granulomatous Disorders. Ann NY Acad Sci 1976;278:742.

2 Isle of Man Registrar. Reports of the Isle of Man Census. Isle of Man Registrar, General Registry, Douglas: Isle of Man Registrar, General Registry, 1961, 1966, 1971, 1976, 1981.

3 Romer FK. Notification of sarcoidosis in Denmarkthe true incidence. $Z$ Erkr Atmungsorgane 1977; 149:59-66.

4 Horowitz O. Epidemiology of sarcoidosis in Denmark. In: Levinsky L, Macholda F, eds. Proceedings of the Fifth International Conference on Sarcoidosis. Prague: Universita Karlova, 1971:254-8.

5 Selroos $\mathrm{O}$. The frequency of sarcoidosis in Finland. In: Iwai K, Hosoda Y, eds. Proceedings of the Sixth International Conference on Sarcoidosis. Tokyo: University Park Press, 1974:319-21.

6 Levinsky L, Cummiskey J, Romer FK, et al. Sarcoidosis in Europe: a co-operative study. In: Siltzbach LE, ed. Proceedings of the Seventh International Conference on Sarcoidosis. Ann NY Acad Sci 1976;278:335-46. 
7 Blasi A, Giobbi A, Olivieri D, et al. On the incidence of sarcoidosis in Italy. In: Iwai K, Hosoda Y, eds. Proceedings of the Sixth International Conference on Sarcoidosis. Tokyo: University Press, 1974:317-8.

8 British Thoracic and Tuberculosis Association. Geographical variations in the incidence of sarcoidosis in Great Britain: a comparative study of four areas. Tubercle 1969;50:211-31.

9 Sutherland I, Mitchell DN, Hart PD' A. Incidence of intrathoracic sarcoidosis among young adults participating in a trial of tuberculosis vaccine. $\mathrm{Br}$ Med J 1965;ii:497-503.

10 Hosoda Y, Iwai K, Odaka M, et al. Recent epidemiological features of sarcoidosis in Japan. In: Williams WJ, Davies $\mathrm{BH}$, eds. Proceedings of the Eighth International Conference on Sarcoidosis and Other Granulomatous Disorders. Cardiff: Alpha Omega Publishing, 1980:519-22.

11 Hiraga Y, Hosoda Y, Odaka M, et al. Epidemiology of sarcoidosis in a Japanese working group: a ten year study. In: Iwai K, Hosoda Y, eds. Proceedings of the Sixth International Conference of Sarcoidosis. Tokyo: University Park Press, 1974:303-6.

12 Hillerdal G, Nöu E, Osterman K, Schmekel B. Sarcoidosis: epidemiology and prognosis. Am Rev Respir Dis 1984;130:29-32. 